\title{
Soroprevalência da neosporose em bovinos de leite criados em sistema de agricultura familiar
}

Vera Cláudia Magalhães Curci[a]", Fernando Morelli[b], Luis Henrique Romeiro dos Santos ${ }^{[[],}$, Brenno Angelo de Moraes ${ }^{[c]}$, Adriana Hellmeister de Campos Nogueira[c], Liria Hiromi Okuda ${ }^{[c]}$, Eliana De Stefano ${ }^{[c]}$, Edviges Maristela Pituco ${ }^{[c]}$

\footnotetext{
[a] Unidade de Pesquisa e Desenvolvimento de Araçatuba, Agência Paulista de Tecnologia dos Agronegócios (APTA), Secretaria de Agricultura e Abastecimento do Estado de São Paulo (SAA), São Paulo, SP, Brasil

${ }^{[b]}$ Instituto de Terras do Estado de São Paulo (ITESP), Andradina, SP, Brasil

[c] Instituto Biológico/APTA/SAA, São Paulo, SP, Brasil
}

*Autor correspondente

e-mail: vlmcurci@apta.sp.gov.br

\section{Resumo}

A pecuária leiteira, como uma das principais atividades desenvolvidas em assentamentos na região noroeste paulista, além de produzir fonte de alimento próprio, é comercializada e garante a sustentabilidade econômica da propriedade. Os esforços estão concentrados na melhoria da nutrição e genética das matrizes, no entanto, não faz parte da rotina dos assentados a verificação do status sanitário desses animais em relação às doenças infecciosas, que podem causar perdas econômicas significativas em consequência de transtornos reprodutivos. Devido a relatos de falhas na reprodução, o estudo objetivou avaliar a frequência de anticorpos contra $N$. caninum, pela técnica de imunofluorescência indireta (RIFI), em rebanhos leiteiros criados em sistema de agricultura familiar, uma vez que este protozoário é considerado um dos principais envolvidos em casos de abortamento na espécie bovina. Participaram do estudo 945 animais (46,92\% do rebanho) de 64 propriedades produtoras de leite. Destes, 332 animais (35,13\%) foram reagentes na RIFI. Quando avaliadas as propriedades amostradas, 58 (90,62\%) apresentaram pelo menos um animal reagente, demonstrando que a neosporose bovina está presente na maior parte das propriedades do assentamento em estudo. Algumas características próprias da agricultura familiar, e verificadas neste assentamento por meio de questionário, podem ser consideradas determinantes na transmissão de doenças como a neosporose, entre elas a aquisição de animais sem atestado sanitário (90,62\%), contribuindo na manutenção da doença pela transmissão vertical em vacas portadoras, compartilhamento de pastos entre os produtores $(28,12 \%)$, além do estreito convívio com animais domésticos como os cães $(98,43 \%)$, que podem atuar na manutenção da transmissão horizontal. Concluímos que a frequência de neosporose no rebanho estudado condiz com 
os dados obtidos na literatura nacional, mostrando a presença e a importância de se implantar medidas de controle nos rebanhos analisados. A necessidade de promover educação em saúde no assentamento é evidente a fim de que os produtores façam uso de boas práticas sanitárias, permitindo melhorias à produção e reprodução dos animais e consequente melhoria na geração de renda e na oferta de produtos saudáveis para o consumo humano. 